\title{
Analysis of the Anti-seismic Property of the Corner Post in the Main Control Building of Assembled Steel Structure Transformer Substation
}

\author{
Chen Youhui $^{\text {1,a,*, }}$ Meng Xiangkun ${ }^{2, b}$, Chen Mingyue ${ }^{3, c}$, Yang Yiye ${ }_{1, \mathrm{i}}^{\text {1,d }}$, LU Tianqi ${ }^{1, e}$, Jiang \\ $\mathrm{Li}^{1, \mathrm{f}}$, Pan Qi ${ }^{1, \mathrm{~g}}$, Xiao Xue ${ }^{1, \mathrm{~h}}$, Yan Chuang ${ }^{1, \mathrm{i}}$ \\ ${ }^{1}$ State Grid Liaoning Electric Power Company Limited Economic Research Institute, Shenhe, Shengyang, \\ China \\ ${ }^{2}$ Northeast Dianli University School of Civil Engineering and Architecture, Chuanying, Jilin, China \\ ${ }^{3}$ State Grid Liaoning Integrated Energy Service Co., Ltd., Heping, Shengyang, China \\ a chenyouhui06@163.com, ${ }^{\mathrm{b}}$ 407927671@qq.com, ${ }^{\mathrm{c}}$ szll2011@sina.com, ${ }^{\mathrm{d}}$ \\ 2711989240@qq.com,_e 1425651955@qq.com, ${ }^{\mathrm{f}}$ 76425865@qq.com, ${ }^{\mathrm{g}}$ chenyh1129@sina.com, ${ }^{\mathrm{h}}$ \\ 372789053@qq.com,_i174936457@qq.com \\ *corresponding author
}

Keywords: assembled; steel structure; anti-seismic property; corner post

\begin{abstract}
The main control building of Chaoyang-Yuzhou $220 \mathrm{kV}$ substation is taken as the research object, and the three-dimensional integrated model of the prefabricated steel structure main control building is built using finite element software ANSYS. Time-history analysis was used to analyse the seismic performance of the corner column structure model of the main control building based on 7-degree seismic fortification. The results show that the maximum displacement value of the column top of the corner column of the main control building of the prefabricated steel structure substation is less than the specification limit. The corner columns significantly reduce the shear force at the bottom of the column, which contributes to the improvement of the overall seismic resistance of the structure and improves the seismic performance of traditional corner columns. Complying with the overall seismic requirements of the substation, this paper provides a theoretical argument for the application of the main control building of the prefabricated steel structure substation in the north.
\end{abstract}

\section{Introduction}

The main control building is an important part of the substation. After the completion of the construction of the main control building of the traditional cast-in-place concrete substation, there are many problems such as construction costs, building quality and safety ${ }^{[1]}$.The construction and construction period of the prefabricated substation main control building is short, and its prefabricated components have already been completed in the factory, avoiding the influence of various uncontrollable factors on the quality of the components. The construction process conforms to the concept of green environmental protection, reduces the noise generated by the project, and effectively guarantees the project quality and management costs. At present, the prefabricated steel structure main control building has been built and operated in many places such as Jiangsu and Shanghai. However, due to the gap between the weather environment and the assembly technology level in the southern and northern regions of China, the construction technology of the main control building of the assembly substation in the northern region is still not mature. Therefore, we should conduct in-depth research on assembly technology ${ }^{[2]}$.

This article uses the finite element software ANSYS to establish the three-dimensional overall model of the main control building. Because the corner post is under the action of earthquake, it is in the state of complex stress due to bending, shearing, shearing and torsion, which may easily cause structural damage and cause the collapse of the main control building. For this reason, the seismic response analysis of the assembled structure corner column is carried out to explore the 
overall seismic performance of the steel structure main control building and the seismic performance of the corner column. Finally, it lays a solid foundation for research and promotion of the new assembled steel structure main control building in the north.

\section{Project Overview}

This article takes the Chaoyang-Yuzhou 220kV substation main control building as an example. As the main control building of the first fabricated steel structure substation in the north, the main structure and exterior wall are assembled as shown in Figure 1. Steel column adopts HM194×150 truss, The lower chord adopts L80 $\times 80 \times 7$ galvanized angle steel, and the upper and lower chords of the truss adopt C-type purlins. The lower string between the roof trusses is increased. Both the column cable and the truss cable use 8.8 large hexagonal high-strength bolts, and the rest are connected by ordinary bolts. The seismic intensity is 7 degrees, and the basic earthquake acceleration value is $0.10 \mathrm{~g}$.

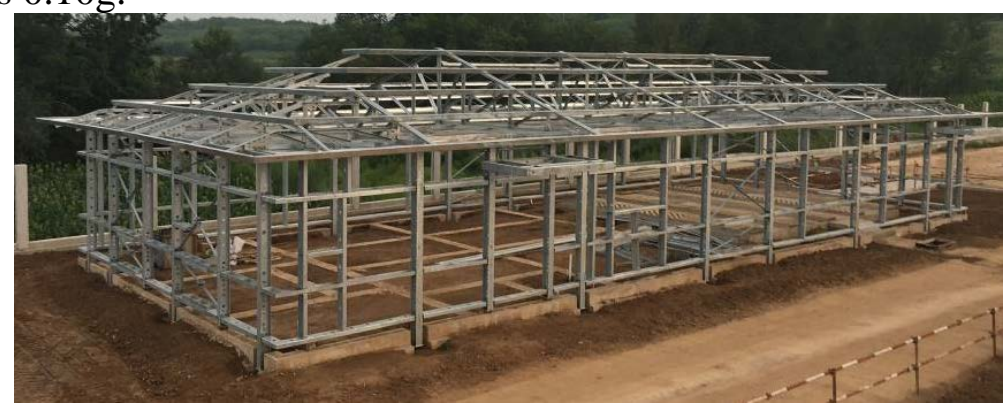

Figure 1 The Main Control Building of Assembled Steel Structure Transformer Substation

\section{Modal Analysis of Main Structure of Prefabricated Steel Structure}

Due to the complexity of the main control building structure of the substation, there are many prefabricated components such as C-type purlins and unequal-angle steels, and the size difference is huge. After its successful operation, it must be promoted in a large area in the north. According to the requirements of the Classification Standard for Construction Engineering Protection, the seismic intensity of the main structure of the prefabricated steel structure shall meet the requirements of 7 degrees or more in order to meet the substation use standards. Therefore, in order to better reflect the seismic performance of the substation main control building, the overall structural model of this paper will be drawn according to the depth of the construction drawing. Considering the real situation of the construction site, the bottom of the steel column is fixed.

The mode shape of the structure determines its deformation mode, applies dynamic load on the structure, and analyses the force path and failure mode of the structure through the deformation of the structure ${ }^{[3]}$. This article uses the finite element software ANSYS to perform modal analysis on the structure, and provides the basic performance parameters of the structure to help us study the dynamic characteristics of the structure. The modal analysis shows that the main vibration mode in the $\mathrm{X}$ direction is shown in Figure 2, and the main vibration mode in the $\mathrm{Y}$ direction is shown in Figure 3.

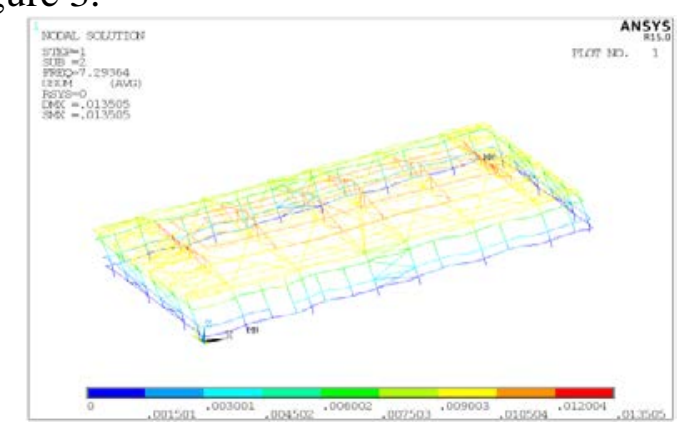

Figure $2 \mathrm{X}$ direction of the main vibration mode

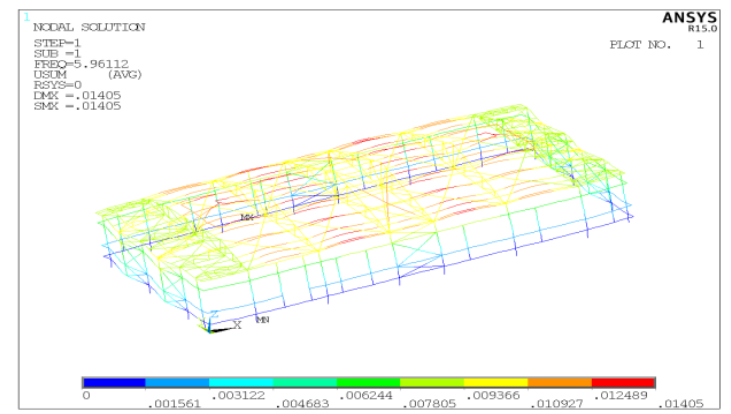

Figure 3 Y direction of the main vibration mode 
It can be seen from the main vibration pattern that as the color becomes lighter from bottom to top, the displacement of the structure increases in turn. In the X-direction main vibration mode, the maximum displacement mainly occurs on the truss, and the maximum displacement in the $\mathrm{Y}$ direction main mode mainly occurs on the purlins connecting the roof trusses.

\section{The analysis of main structure of prefabricated steel structure}

Time-history analysis can use stepwise integration to solve the seismic response of a structure or component at any time. In general, the spectral characteristics of seismic waves can reflect the excellent cycle on the site where the building is located, and its peak acceleration can often reflect the seismic intensity of the site ${ }^{[4-5]}$. The traditional corner posts are arranged at the corners of the frame structure and are used to bear the forces of two beams that are perpendicular or oblique to each other. The corner column of the fabricated steel structure divides the traditional corner column into two, and is disposed on both sides of the corner of the structure instead of the corner column, as shown in Figure 4. In this paper, the finite element software ANSYS is used to analyse the timehistory of the corner column of the main control building under the 7 degree earthquake.

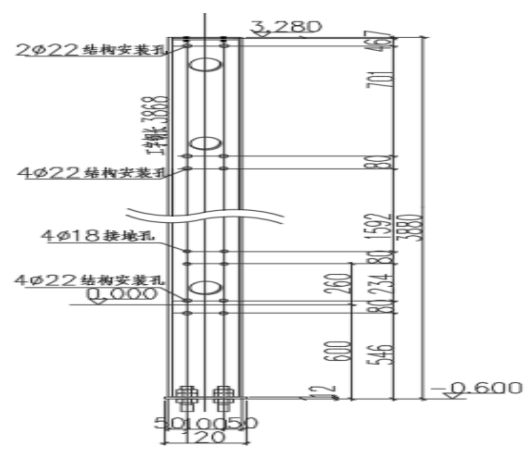

Figure 4 Engineering drawings

\subsection{Time-history analysis results under 7 degrees of multiple earthquakes}

In order to consider the influence of the randomness of seismic waves, according to the provisions of the number of seismic waves in the "Code for Seismic Design of Buildings",[6], In this paper, for the three-dimensional model of the main control building, three kinds of waveforms, namely EI wave, Taft wave and artificial wave, are selected to record the seismic acceleration. Select seismic intensity of 7 degrees, according to the maximum acceleration, make intensity adjustments to the time course of acceleration. All discrete points of the seismic wave on the time history curve are changed in the same proportion to meet the seismic intensity requirements of the site where the building is located. The seismic wave related parameters selected for this purpose are shown in Table 1.

Table1 Seismic wave related parameters

\begin{tabular}{|c|c|c|c|}
\hline Seismic wave name & Time Step(s) & Continued duration(s) & Acceleration peak $\left(\mathrm{cm} / \mathrm{s}^{2}\right)$ \\
\hline Taft wave & 0.02 & 20 & 1439 \\
\hline EI wave & 0.02 & 20 & 341.7 \\
\hline Artificial wave & 0.02 & 20 & 392.7 \\
\hline
\end{tabular}

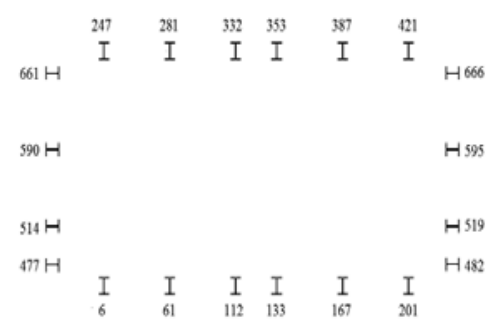

Figure5 Column top node number

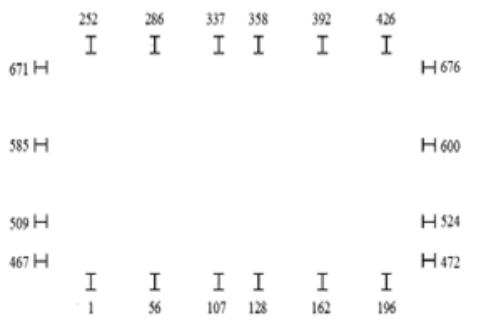

Figure6 Column bottom node number 
The number of the top of the column and the bottom of the column is shown in Figures 5 and 6 . The elastic time history analysis of the structural model under 7-degree earthquake is carried out, and the maximum displacement value and maximum displacement moment of the column top node in the $\mathrm{X}$ direction, $\mathrm{Y}$ direction and 45 degree direction under the excitation of EI wave, Taft wave and artificial wave are obtained. The overall equivalent stress cloud and bottom column shear.

\subsection{The maximum displacement of the top node}

Due to the symmetry of the structure, the top nodes of $6,61,112,477,514,590$, and 661 are used as control nodes, and they are excited in the $\mathrm{X}$ direction, $\mathrm{Y}$ direction, and 45 degrees under the excitation of EI wave, Taft wave, and artificial wave. The maximum displacement of the top node of the three directions is shown in Tables 2, 3 and 4.

Table 2 The maximum displacement of column top when the three waveforms are excited in the direction of 45 degrees $(\mathrm{cm})$

\begin{tabular}{|c|c|c|c|c|c|c|c|}
\hline \multirow{2}{*}{$\begin{array}{c}\text { Waveform and } \\
\text { direction }\end{array}$} & \multicolumn{2}{c|}{ EI wave } & \multicolumn{2}{c|}{ Taft wave } & \multicolumn{2}{c|}{ Artificial wave } \\
\cline { 2 - 7 } & $\mathrm{X}$ & $\mathrm{Y}$ & $\mathrm{X}$ & $\mathrm{Y}$ & $\mathrm{X}$ & $\mathrm{Y}$ \\
\hline \multirow{2}{*}{6} & $\max$ & 0.021 & 0.072 & 0.015 & 0.072 & 0.024 & 0.068 \\
\cline { 2 - 7 } & $\min$ & -0.024 & 0.006 & -0.024 & -0.005 & -0.032 & -0.003 \\
\hline \multirow{2}{*}{61} & $\max$ & 0.022 & 0.073 & 0.016 & 0.074 & 0.025 & 0.072 \\
\cline { 2 - 7 } & $\min$ & -0.023 & -0.006 & -0.023 & -0.013 & -0.031 & -0.012 \\
\hline \multirow{2}{*}{112} & $\max$ & 0.024 & 0.074 & 0.017 & 0.074 & 0.026 & 0.077 \\
\cline { 2 - 7 } & $\min$ & -0.021 & -0.009 & -0.021 & -0.016 & -0.028 & -0.015 \\
\hline \multirow{2}{*}{477} & $\max$ & 0.023 & 0.084 & 0.016 & 0.085 & 0.026 & 0.075 \\
\cline { 2 - 7 } & $\min$ & -0.024 & 0.008 & -0.023 & 0.008 & -0.032 & 0.003 \\
\hline \multirow{2}{*}{514} & $\max$ & 0.028 & 0.085 & 0.021 & 0.085 & 0.031 & 0.074 \\
\cline { 2 - 7 } & $\min$ & -0.021 & 0.008 & -0.020 & 0.008 & -0.028 & 0.003 \\
\hline \multirow{2}{*}{590} & $\max$ & 0.031 & 0.086 & 0.024 & 0.086 & 0.035 & 0.076 \\
\cline { 2 - 7 } & $\min$ & -0.017 & 0.009 & -0.017 & 0.009 & -0.025 & 0.003 \\
\hline \multirow{2}{*}{661} & $\max$ & 0.025 & 0.086 & 0.017 & 0.086 & 0.027 & 0.076 \\
\cline { 2 - 7 } & $\min$ & -0.022 & 0.009 & -0.022 & 0.008 & -0.030 & 0.003 \\
\hline
\end{tabular}

Table 3 The maximum displacement of column top when the three waveforms are excited in the X $\operatorname{direction}(\mathrm{cm})$

\begin{tabular}{|c|c|c|c|c|c|c|c|}
\hline \multirow{2}{*}{$\begin{array}{c}\text { Waveform and } \\
\text { direction }\end{array}$} & \multicolumn{2}{|c|}{ EI wave } & \multicolumn{2}{c|}{ Taft wave } & \multicolumn{2}{c|}{ Artificial wave } \\
\cline { 2 - 7 } & X & $\mathrm{Y}$ & $\mathrm{X}$ & $\mathrm{Y}$ & $\mathrm{X}$ & $\mathrm{Y}$ \\
\hline \multirow{2}{*}{6} & $\mathrm{max}$ & 0.031 & 0.066 & 0.022 & 0.066 & 0.036 & 0.068 \\
\cline { 2 - 7 } & $\min$ & -0.033 & 0.001 & -0.033 & 0.000 & -0.044 & -0.002 \\
\hline \multirow{2}{*}{61} & $\max$ & 0.032 & 0.069 & 0.023 & 0.070 & 0.036 & 0.073 \\
\cline { 2 - 7 } & $\min$ & -0.031 & -0.006 & -0.031 & -0.006 & -0.042 & -0.007 \\
\hline \multirow{2}{*}{112} & $\max$ & 0.033 & 0.072 & 0.024 & 0.072 & 0.037 & 0.077 \\
\cline { 2 - 7 } & $\min$ & -0.029 & -0.006 & -0.029 & -0.006 & -0.040 & -0.009 \\
\hline \multirow{2}{*}{477} & $\max$ & 0.033 & 0.074 & 0.024 & 0.074 & 0.037 & 0.075 \\
\cline { 2 - 8 } & $\min$ & -0.032 & 0.008 & -0.032 & 0.008 & -0.044 & 0.003 \\
\hline \multirow{2}{*}{514} & $\max$ & 0.039 & 0.074 & 0.029 & 0.074 & 0.043 & 0.075 \\
\cline { 2 - 7 } & $\min$ & -0.029 & 0.008 & -0.029 & 0.008 & -0.041 & 0.003 \\
\hline \multirow{2}{*}{590} & $\max$ & 0.042 & 0.075 & 0.032 & 0.075 & 0.046 & 0.076 \\
\cline { 2 - 7 } & $\min$ & -0.026 & 0.009 & -0.026 & 0.008 & -0.038 & 0.003 \\
\hline \multirow{2}{*}{661} & $\max$ & 0.035 & 0.075 & 0.025 & 0.075 & 0.038 & 0.077 \\
\cline { 2 - 7 } & $\min$ & -0.030 & 0.009 & -0.030 & 0.008 & -0.041 & 0.003 \\
\hline
\end{tabular}


Table 4 The maximum displacement of column top when the three waveforms are excited in the Y direction $(\mathrm{cm})$

\begin{tabular}{|c|c|c|c|c|c|c|c|}
\hline \multicolumn{2}{|c|}{$\begin{array}{c}\text { Waveform and } \\
\text { direction }\end{array}$} & \multicolumn{2}{c|}{ EI wave } & \multicolumn{2}{c|}{ Taft wave } & \multicolumn{2}{c|}{ Artificial wave } \\
\cline { 2 - 7 } & $\mathrm{X}$ & $\mathrm{Y}$ & $\mathrm{X}$ & $\mathrm{Y}$ & $\mathrm{X}$ & $\mathrm{Y}$ \\
\hline \multirow{2}{*}{6} & $\mathrm{max}$ & -0.001 & 0.088 & -0.001 & 0.089 & -0.001 & 0.077 \\
\cline { 2 - 7 } & $\min$ & -0.006 & -0.012 & -0.006 & -0.022 & -0.006 & -0.020 \\
\hline \multirow{2}{*}{61} & $\max$ & -0.004 & 0.091 & 0.000 & 0.092 & -0.003 & 0.079 \\
\cline { 2 - 7 } & $\min$ & -0.005 & -0.021 & -0.003 & -0.032 & -0.004 & -0.031 \\
\hline \multirow{2}{*}{112} & $\max$ & 0.001 & 0.093 & 0.001 & 0.094 & 0.000 & 0.080 \\
\cline { 2 - 7 } & $\min$ & 0.000 & -0.024 & 0.000 & -0.035 & -0.001 & -0.030 \\
\hline \multirow{2}{*}{477} & $\max$ & 0.000 & 0.103 & 0.000 & 0.100 & 0.000 & 0.089 \\
\cline { 2 - 7 } & $\min$ & -0.003 & 0.001 & -0.003 & -0.008 & -0.004 & -0.006 \\
\hline \multirow{2}{*}{514} & $\max$ & 0.004 & 0.105 & 0.004 & 0.101 & 0.004 & 0.089 \\
\cline { 2 - 7 } & $\min$ & 0.000 & 0.001 & 0.000 & -0.008 & 0.000 & -0.006 \\
\hline \multirow{2}{*}{590} & $\max$ & 0.008 & 0.102 & 0.008 & 0.102 & 0.010 & 0.091 \\
\cline { 2 - 7 } & $\min$ & 0.002 & 0.003 & 0.002 & -0.006 & 0.000 & -0.005 \\
\hline \multirow{2}{*}{661} & $\max$ & 0.000 & 0.102 & 0.000 & 0.102 & 0.000 & 0.091 \\
\cline { 2 - 7 } & $\min$ & -0.001 & 0.003 & -0.002 & -0.006 & -0.002 & -0.004 \\
\hline
\end{tabular}

By analyzing the above tables, it can be seen that when excited by EI wave, Taft wave and artificial wave in the $\mathrm{X}$ direction, $\mathrm{Y}$ direction and 45 degree direction, The maximum positive displacement is $0.046 \mathrm{~cm}$ in the $\mathrm{X}$ direction and $0.105 \mathrm{~cm}$ in the $\mathrm{Y}$ direction. The maximum negative displacement is $-0.044 \mathrm{~cm}$ in the $\mathrm{X}$ direction and $-0.035 \mathrm{~cm}$ in the $\mathrm{Y}$ direction. The maximum displacement of the structure mainly occurs in the $\mathrm{Y}$ direction. According to the "Technical Standard for Prefabricated Steel Structures" ${ }^{[7]}$ and "Steel Structure Design Code" ${ }^{[8]}$, the displacement of the top of a single-story frame column shows that the column height of this corner column is $3.8 \mathrm{~m}$, and the column top displacement meets the requirements.

\subsection{Column bottom shear}

Table 5 EI wave bottom shear force comparison table

\begin{tabular}{|c|c|c|c|c|c|c|}
\hline EI wave & \multicolumn{6}{|c|}{ No. 1 corner column bottom shear(N) } \\
\hline & $\mathrm{X}$ & $\mathrm{Y}$ & $45^{\circ}$ & \multicolumn{2}{c|}{ Percentage(\%) } \\
\hline & $\mathrm{F}_{\mathrm{X}}$ & $\mathrm{F}_{\mathrm{Y}}$ & $\mathrm{F}_{\mathrm{X}}$ & $\mathrm{F}_{\mathrm{Y}}$ & $\mathrm{X}$ & $\mathrm{Y}$ \\
\hline Shear(max) & 603.06 & 474.81 & 488.18 & 359.30 & 80.95 & 75.67 \\
\hline Shear(min) & -279.19 & -207.36 & -141.85 & -154.84 & 50.81 & 74.67 \\
\hline & \multicolumn{7}{|c|}{ No. 467 corner column bottom shear(N) } \\
\hline & $\mathrm{X}$ & $\mathrm{Y}$ & $45^{\circ}$ & \multicolumn{2}{c|}{ Percentage(\%) } \\
\hline & $\mathrm{F}_{\mathrm{X}}$ & $\mathrm{F}_{\mathrm{Y}}$ & $\mathrm{F}_{\mathrm{X}}$ & $\mathrm{F}_{\mathrm{Y}}$ & $\mathrm{X}$ & $\mathrm{Y}$ \\
\hline & -136.17 & 636.26 & -94.66 & 535.43 & 69.52 & 84.15 \\
\hline Shear(max) & -595.38 & -365.14 & -506.33 & -206.67 & 85.04 & 56.60 \\
\hline Shear(min) & &
\end{tabular}

Table 6 Taft wave column shear force comparison table

\begin{tabular}{|c|c|c|c|c|c|c|}
\hline \multirow[t]{3}{*}{ Taft wave } & \multicolumn{6}{|c|}{ No. 1 corner column bottom shear(N) } \\
\hline & $\mathrm{X}$ & $\mathrm{Y}$ & $45^{\circ}$ & & \multicolumn{2}{|c|}{ Percentage(\%) } \\
\hline & $\mathrm{F}_{\mathrm{X}}$ & $\mathrm{F}_{\mathrm{Y}}$ & $\mathrm{F}_{\mathrm{X}}$ & $\mathrm{F}_{\mathrm{Y}}$ & $\mathrm{X}$ & $\mathrm{Y}$ \\
\hline Shear(max) & 607.66 & 522.98 & 492.06 & 463.51 & 80.98 & 88.63 \\
\hline \multirow[t]{4}{*}{ Shear(min) } & -163.18 & -211.03 & -57.40 & -192.06 & 35.17 & 91.01 \\
\hline & \multicolumn{6}{|c|}{ No. 467 corner column bottom shear(N) } \\
\hline & $\mathrm{X}$ & $\mathrm{Y}$ & $45^{\circ}$ & & \multicolumn{2}{|c|}{ Percentage $(\%)$} \\
\hline & $\mathrm{F}_{\mathrm{X}}$ & $\mathrm{F}_{\mathrm{Y}}$ & $\mathrm{F}_{\mathrm{X}}$ & $\mathrm{F}_{\mathrm{Y}}$ & $\mathrm{X}$ & $\mathrm{Y}$ \\
\hline Shear(max) & -109.33 & 716.67 & -89.96 & 552.93 & 82.29 & 77.15 \\
\hline Shear(min) & -528.04 & -386.64 & -462.23 & -224.49 & 87.54 & 58.06 \\
\hline
\end{tabular}


Table7 Artificial wave column shear force comparison table

\begin{tabular}{|c|c|c|c|c|c|c|}
\hline \multirow[t]{3}{*}{ artificial wave } & \multicolumn{6}{|c|}{ No. 1 corner column bottom shear(N) } \\
\hline & $\mathrm{X}$ & $\mathrm{Y}$ & \multicolumn{2}{|c|}{$45^{\circ}$} & \multicolumn{2}{|c|}{ Percentage $(\%)$} \\
\hline & $\mathrm{F}_{\mathrm{X}}$ & $\mathrm{F}_{\mathrm{Y}}$ & $\mathrm{F}_{\mathrm{X}}$ & $\mathrm{F}_{\mathrm{Y}}$ & $\mathrm{X}$ & $\mathrm{Y}$ \\
\hline Shear(max) & 752.97 & 534.85 & 598.47 & 429.53 & 79.48 & 80.31 \\
\hline \multirow[t]{4}{*}{ Shear(min) } & -326.24 & -288.39 & -181.78 & -229.02 & 55.72 & 79.42 \\
\hline & \multicolumn{6}{|c|}{ No. 467 corner column bottom shear(N) } \\
\hline & $\mathrm{X}$ & $\mathrm{Y}$ & \multicolumn{2}{|c|}{$45^{\circ}$} & \multicolumn{2}{|c|}{ Percentage( $\%)$} \\
\hline & $\mathrm{F}_{\mathrm{X}}$ & $\mathrm{F}_{\mathrm{Y}}$ & $\mathrm{F}_{\mathrm{X}}$ & $\mathrm{F}_{\mathrm{Y}}$ & $\mathrm{X}$ & $\mathrm{Y}$ \\
\hline Shear(max) & 89.69 & 826.06 & 32.82 & 725.87 & 36.59 & 87.87 \\
\hline Shear(min) & -623.37 & -265.77 & -519.83 & -234.01 & 83.39 & 88.05 \\
\hline
\end{tabular}

Analysis of the structure of corner columns, due to the symmetry of the structure only need to analyse a pair of corner columns, select column No. 1 and No. 467 column for analysis, Under the excitation of EI wave, Taft wave and artificial wave, the column bottom shear force in the $\mathrm{X}$ direction, Y direction and 45 degree direction is shown in Tables 5, 6, and 7.

Under the EI wave, Taft wave and artificial excitation in the X-direction, Y-direction, and 45degree direction, the three-cornered column is subjected to column bottom shear force comparison table. When the seismic wave acts on the structure at 45 degrees, the maximum column bottom is affected. Shear force is $8.99 \%$ 64.83\% smaller than that in the X direction and Y direction alone. That is, when the corner column is used instead of the corner column, the shear force at the bottom of the column is greatly reduced, the seismic performance of the traditional corner column is improved, and the overall seismic performance of the structure is improved.

\section{Conclusion}

Under the action of an earthquake with a seismic fortification intensity of 7 degrees, most of the components of the prefabricated main control building are in a low-stress state and are structurally elastic. The maximum displacement value of the corner column top is far less than the required limit, and the corner column can reduce the shear strength at the bottom of the column. When the structure is subjected to a rare earthquake of 7 degrees, the structure enters a plastic state and meets the overall seismic requirements of the main control building. Due to limited time, this paper only made earthquake time-history analysis for a 7 degree earthquake. In order to explore a wider range of adaptability, simulation analysis can be carried out under the conditions of 8 degrees and rare earthquakes to meet the seismic requirements for the application of prefabricated main control buildings.

\section{References}

[1] Zhang Feiqiang. (2011)Fabricated substation exploration and installation technology. Zhejiang University.

[2] Zhao Kai. (2016)Discussion on Civil Design of Assembly Substation.Low Carbon World. Health, 11, 68-69.

[3] Shi Wei. (2013)Analysis of Seismic Performance of Single-Storey Steel Structure Factory Building. Xi'an University of Architecture and Technology.

[4] Zhang Zhongliang. (2016)Research on Seismic Design Method for Long Span Structures. Sichuan Cement. Health, 9, 329-329.

[5] Peng Deng, Ma Kejian, Yuan Bo, et al. (2012)Elastoplastic time history analysis of complex structures under rare earthquakes. Journal of Guizhou University (Natural Science), Health, 2,114117.

[6] MOHURD. Code for seismic design of buildings: GB 50011-2010. Beijing: China Architecture 
\& Building Press, 2010.

[7] MOHURD. Technical standard for assembled buildings with steel-structure: GB/T 51232-2016. Beijing: China Architecture \& Building Press, 2017.

[8] Ministry of Construction of People's Republic of China. Code for design of steel structure: GB 50017-2003, Beijing: China Planning Press, 2003. 